\title{
Transatrial implantation of a transcatheter heart valve for severe mitral annular calcification
}

\author{
Fabien Praz, MD, ${ }^{\mathrm{a}}$ Omar K. Khalique, MD, ${ }^{\mathrm{a}}$ Raymond Lee, MD, ${ }^{\mathrm{b}}$ Ramesh Veeragandham, MD, \\ Hyde Russell, MD, ${ }^{\mathrm{d}}$ Mayra Guerrero, MD, ${ }^{\mathrm{d}}$ Ashequl M. Islam, MD, ${ }^{\mathrm{e}}$ David W. Deaton, MD, ${ }^{\mathrm{e}}$ \\ Tsuyoshi Kaneko, MD, ${ }^{\mathrm{f}}$ Susheel K. Kodali, MD, ${ }^{\mathrm{a}}$ Martin B. Leon, MD, ${ }^{\mathrm{a}}$ Vinayak Bapat, MD, ${ }^{\mathrm{a}}$ \\ Hiroo Takayama, MD, ${ }^{a}$ Michael A. Borger, $\mathrm{MD}^{\mathrm{g}}{ }^{\mathrm{a}}$ and Isaac George, $\mathrm{MD}^{\mathrm{a}}$
}

\section{ABSTRACT}

Objective: To assess the outcomes of transatrial implantation of a transcatheter heart valve (THV) for the treatment of mitral valve disease with severe mitral annular calcification (MAC).

Methods: Implantation of a balloon-expandable THV was performed on cardiopulmonary bypass via left atrial exposure in patients considered at risk for left ventricular outflow tract obstruction. The anterior mitral valve leaflet was systematically resected and pledgeted sutures were placed to enhance stability and reduce paravalvular leak.

Results: Twenty-six consecutive symptomatic patients with severe MAC (mean age, $78 \pm 7$ years; $92 \%$ female; mean Society of Thoracic Surgeons score, $9.4 \pm 4.8)$ were included at 6 different centers. Two patients $(8 \%)$ received an Edwards Sapien XT (Edwards Lifesciences, Irvine, Calif), and $24(92 \%)$ an Edwards Sapien 3 bioprosthesis (Edwards Lifesciences). Concomitant aortic valve replacement was performed in 11 patients. Technical success according to the criteria of the Mitral Valve Academic Research Consortium was achieved in all patients. The mean transmitral gradient decreased from $10 \pm 5$ to $4 \pm 2 \mathrm{~mm}$ $\mathrm{Hg}(P<.001)$ with trace or mild regurgitation in all patients. An elevated mean transaortic gradient $(30 \mathrm{~mm} \mathrm{Hg})$ was observed in 1 patient $(4 \%)$. Five patients died during hospital stay $(19 \%)$ and 2 additional between discharge and 30 days (30-day mortality: 27\%). Sustained functional improvement was observed in the remaining patients.

Conclusions: Transatrial implantation of a THV for the treatment of MAC is associated with high technical success despite unfavorable anatomy. In this early experience of very high surgical risk patients, 30-day all-cause mortality was high. Patients at particular risk appear to be those with chronic kidney disease

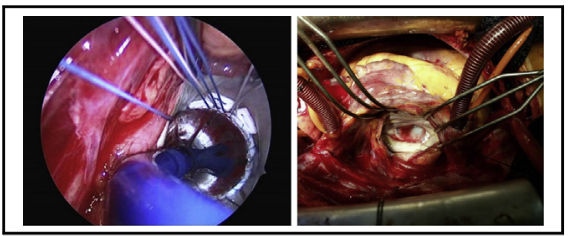

Transatrial valve implantation in a patient with severe mitral annular calcification.

\section{Central Message}

Transatrial mitral implantation of a transcatheter heart valve in patients at risk for LVOT obstruction is feasible. The high 30-day mortality highlights the need for improved patient selection.

\section{Perspective}

Transatrial implantation of a balloonexpandable transcatheter heart valve might address the needs of many symptomatic, currently untreated patients with severe mitral annular calcification not amenable to another approach because of unfavorable anatomy. Thirty-day mortality remains high in this early experience, and further investigation is warranted to improve patient selection and outcomes.

See Editorial Commentary page 143.
From the ${ }^{\mathrm{a}} \mathrm{New}$ York-Presbyterian Hospital/Columbia University Medical Center, New York, NY; ' Novant Health Forsyth Medical Center, Winston Salem, NC; ${ }^{\mathrm{c} J o h n}$ Muir Health Care, Concord, Calif; ${ }^{\mathrm{d}}$ Evanston Hospital Northshore University Health System, Evanston, Ill; ${ }^{\mathrm{e} B a y s t a t e}$ Medical Center, Springfield, Mass; ${ }^{\mathrm{f}}$ Brigham and Women's Hospital, Boston, Mass; and ${ }^{\mathrm{g}}$ Department of Cardiac Surgery, Leipzig Heart Center, Leipzig, Germany.

Fabien Praz is supported by a grant from the Gottfried and Julia Bangerter-RhynerFoundation, Bern, Switzerland.

Received for publication Dec 10, 2017; revisions received Feb 9, 2018; accepted for publication March 6, 2018; available ahead of print April 4, 2018.

Address for reprints: Isaac George, MD, Division of Cardiothoracic Surgery, New York-Presbyterian Hospital-College of Physicians and Surgeons of Columbia University, MHB 7GN-435, 177 Ft Washington Ave, New York, NY 10032 (E-mail: ig2006@cumc.columbia.edu).

$0022-5223 / \$ 36.00$

Copyright (c) 2018 by The American Association for Thoracic Surgery

https://doi.org/10.1016/j.jtcvs.2018.03.016
Mitral annular calcification (MAC) of variable severity is observed in $8 \%$ to $15 \%$ of the general population ${ }^{1-5}$ and follows an age-related increasing prevalence. ${ }^{1}$ Among transcatheter aortic valve implantation candidates and patients with impaired renal function, its frequency is as high as $49 \%$ and $42 \%$, respectively. ${ }^{6,7}$ Beside age, additional predictors of MAC include female sex,

Scanning this $Q R$ code will take you to the supplemental videos for the article.

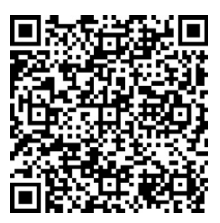



Abbreviations and Acronyms
$\mathrm{CT}=$ computed tomography
LVOT $=$ left ventricular outflow tract
MAC $=$ mitral annular calcification
MR = mitral regurgitation
MS = mitral stenosis
MV = mitral valve
NYHA $=$ New York Heart Association
PVL = paravalvular leak
TAVR $=$ transcatheter aortic valve replacement
$\mathrm{THV}=$ transcatheter heart valve
TTE $=$ transthoracic echocardiography

the transseptal or transapical access, or open transatrial implantation of a balloon-expandable THV under direct visualization. At this early stage, only patients with severe MAC presenting with extensive involvement of the posterior leaflet and, for many of them, concentric calcification also involving the aortomitral curtain or calcifications expanding into the myocardium and the subvalvular apparatus were considered eligible. The final decision of not to perform a conventional surgical valve replacement was made on the basis of direct visual assessment of the anatomy by the 2 operating surgeons. The following additional criteria were considered favoring the transatrial approach: high risk of LVOT obstruction on the basis of preoperative imaging, nonconcentric calcifications or large mitral annular area increasing the risk of valve embolization, and the presence of extensive calcifications of the subvalvular apparatus, possibly interacting with the delivery system during valve positioning and deployment. Data were collected prospectively and the study was approved by the Institutional Review Board and followed the requirements of the Declaration of Helsinki.

\section{Transthoracic and Transesophageal \\ Echocardiography}

All patients underwent transthoracic echocardiography (TTE) and, occasionally, transesophageal echocardiography, at baseline to determine the severity of mitral valve disease. According to current guidelines, ${ }^{24}$ severe MS was defined as a mitral valve area $<1.5 \mathrm{~cm}^{2}$ and a mean transmitral gradient $>5 \mathrm{~mm} \mathrm{Hg}$. In addition, a vena contracta $\geq 7 \mathrm{~mm}$, a calculated regurgitant orifice area $\geq 40 \mathrm{~mm}^{2}$, a regurgitant volume $\geq 60 \mathrm{~mL}$, and/or the presence of systolic flow reversal into the pulmonary veins were considered indicative of severe mitral regurgitation (MR). ${ }^{24-26}$ MR was graded according to the 4 following categories: none/trace, mild $(1+)$, moderate $(2+)$, moderate to severe $(3+)$, and severe $(4+)$. Patients were classified in the mixed disease group if they had moderate MS as well as moderate to severe MR. TTE was performed before discharge and at 30 days.

\section{Cardiac Computed Tomography}

Patients in whom symptomatic mitral valve disease was associated with concentric substantial calcifications of the mitral annulus was recognized using echocardiography and/or fluoroscopy were deemed eligible for the performance of electrocardiogram-gated multislice computed tomography (CT) imaging. The CT scan was performed according to a center-specific protocol. Most of the patients were imaged using a dedicated mitral protocol. In patients with renal impairment, CT without contrast medium was performed for evaluation of the annulus size. Multiplanar reconstruction was used for annular measurements as well as CT-based measurement of the mitral valve annular area during diastole (usually $75 \%$; Figure 1, A). Whenever possible valve simulation (Figure 1, B) and systolic measurement of the LVOT and neo-LVOT areas at the level of maximal simulated valve protrusion (Figure $1, C$ ) were performed. ${ }^{27}$ In our study, a neo-LVOT area $<150 \mathrm{~mm}^{2}$ was considered high risk of LVOT obstruction from a non-surgical approach (transseptal or transapical). All analyses were performed using the dedicated 3-Mensio Structural Heart Mitral Workflow version 8.1 (Pie Medical Imaging, AJ Maastricht, The Netherlands).

\section{Valve Implantation}

The procedure was performed using either a median sternotomy or a right thoracotomy. After central aortic and bicaval cannulation in sternotomy and peripheral cannulation in thoracotomy, patients were put on cardiopulmonary bypass and antegrade cardioplegia was administered to induce cardiac arrest. The mitral valve was exposed through a left atriotomy. Systematic resection of the anterior mitral valve leaflet was performed, leaving a $1-\mathrm{cm}$ rim of tissue. In selected patients with a particularly restricted valve opening, the posterior leaflet was also removed. In the presence of subvalvular calcifications potentially 

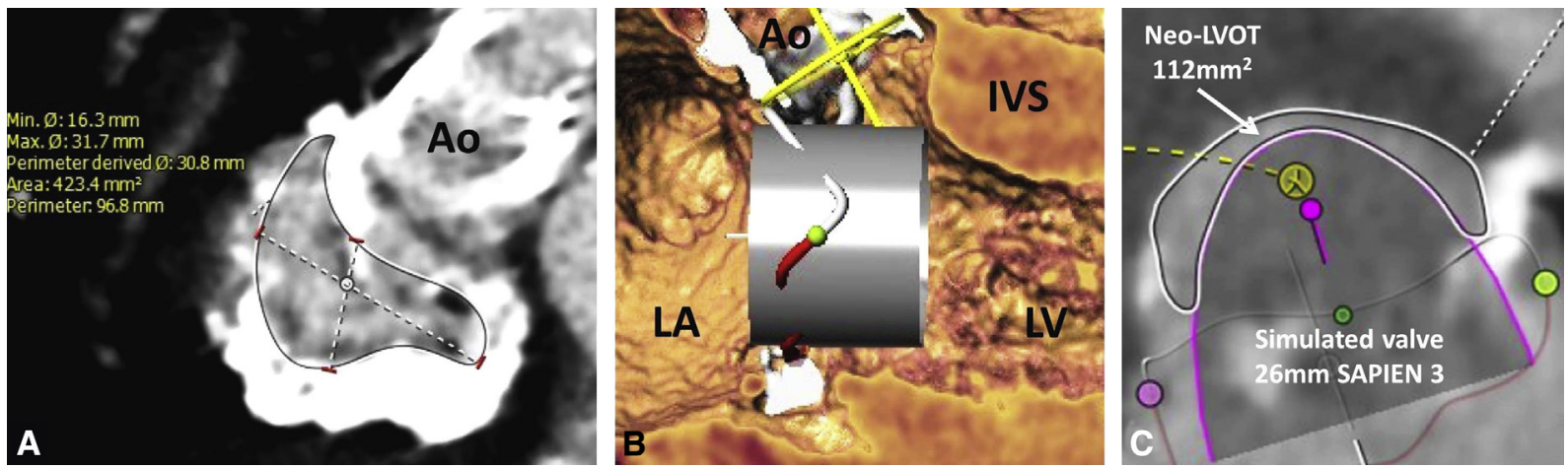

FIGURE 1. The use of cardiac computed tomography (CT) for procedural planning. A, Measurement of the mitral annulus using direct CT planimetry in a patient with previous surgical aortic valve replacement. B, Simulation of the selected transcatheter valve in the reconstructed 3-dimensional anatomy. The yellow plane represents the plane of the aortic bioprosthesis and the red/white interrupted line the mitral plane. C, Neo-left ventricular outflow tract (LVOT) cross-sectional area measured at the level of the maximal valve protusion. Ao, Aorta; IVS, interventricular septum; $L A$, left atrium; $L V$, left ventricle.

interacting with valve deployment, parts of the subvalvular apparatus were selectively resected. Annular debridement aiming to expand the mitral valve orifice was undertaken occasionally. Balloon sizing was performed in all but 1 case using either the standard Edwards balloon (Edwards Lifesciences) or a True Dilatation balloon (BARD Peripheral Vascular, Inc,
Tempe, Ariz). Several (6-12) pledgeted 3-0 TiCron sutures (Medtronic, Minneapolis, Minn) were then placed equidistant around the mitral annulus (Figure 2, A, and Video 1). Preparation of the THV consisted of securing a 0.75 to $1.0-\mathrm{cm}$ soft felt strip to the base of the THV stent frame with a running 5-0 Prolene suture (Ethicon US, LLC, Somerville, NJ; Figure 2,
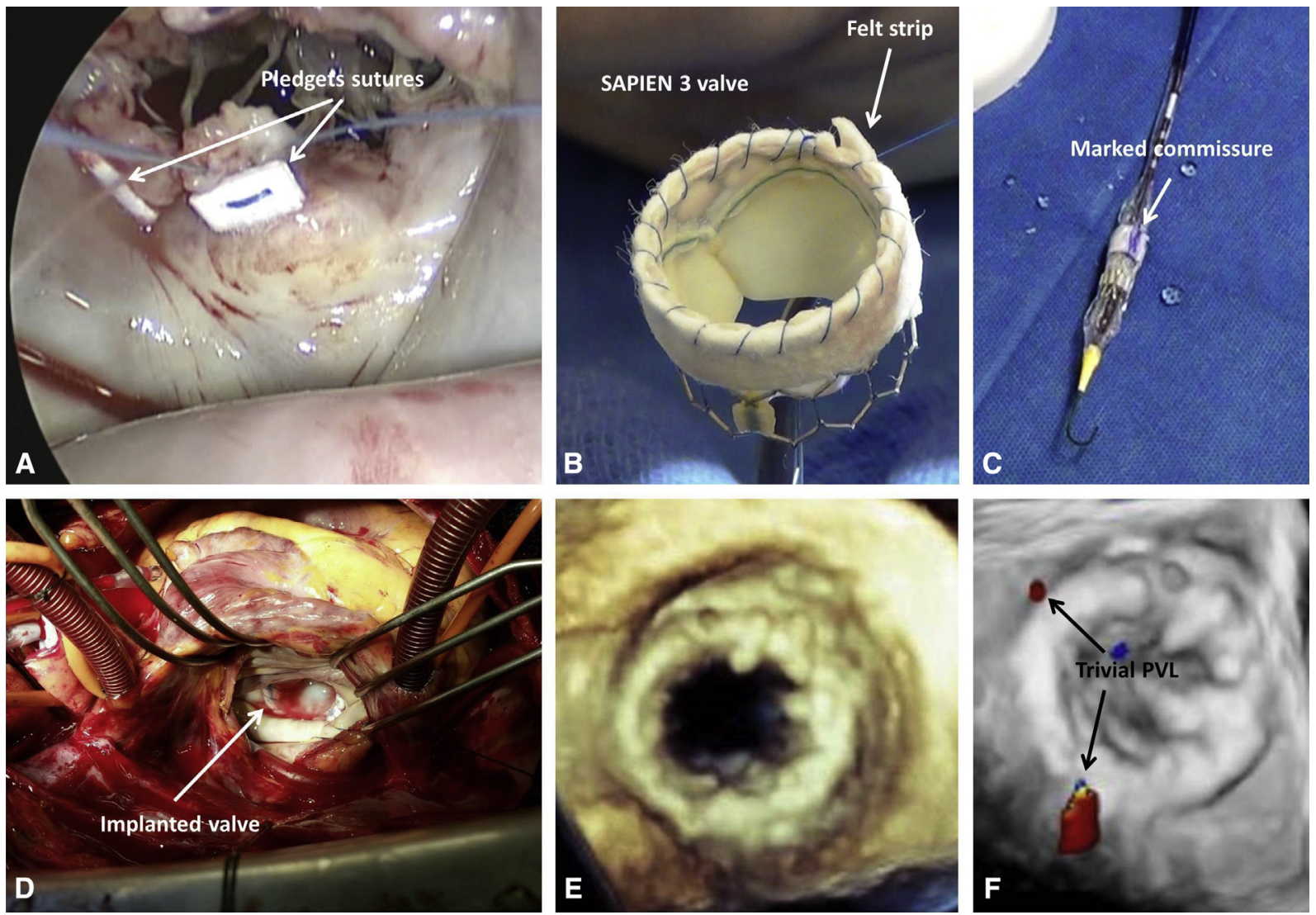

FIGURE 2. Procedural steps. A, Exposure of the mitral valve through a left atriotomy and resection of the anterior mitral valve leaflet. Pledgeted sutures are placed around the annulus into the remaining leaflet tissue. B, A felt strip is sutured around the inflow of the transcatheter valve. $\mathrm{C}$, The valve is crimped in an inverted fashion on the transfemoral catheter or in the usual way on the transthoracic delivery system. The commissures are marked and will be aligned with the trigones anteriorly. A conventional soft wire is used to minimize the risk of ventricular perforation through the nose cone. D, Atrial view of the implanted transcatheter valve after postdilation with optimal apposition at the atrio-ventricular transition. E and F, Final result as seen from the left atrium using transesophageal echocardiography with trace paravalvular leaks $(P V L s)$. 


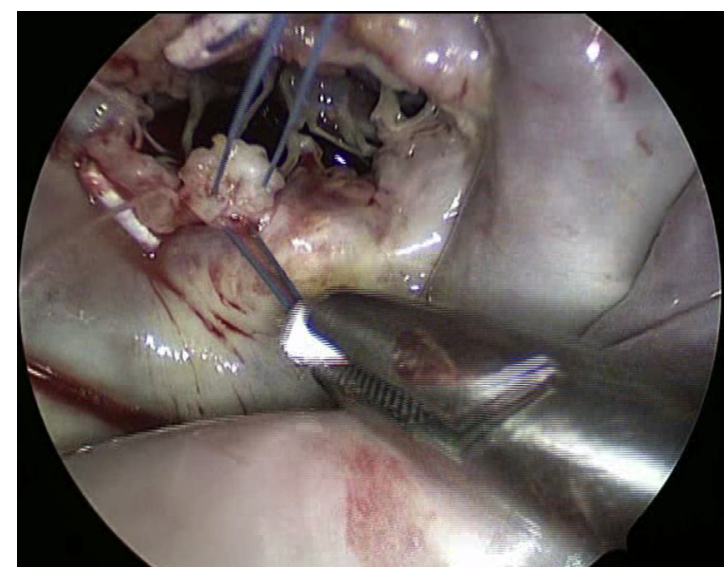

VIDEO 1. Suture placement. After resection of the anterior leaflet, several pledgets sutures are placed into the remaining leaflet tissue with pledgets on the atrial side. Video available at: http://www.jtcvsonline.org/article/ S0022-5223(18)30727-X/fulltext.

$B$, and Video 2) and subsequent crimping on the transfemoral (NovaFlex $+/$ Commander; Edwards Lifesciences) catheter in an inverted fashion or the transthoracic (Certitude) delivery system in the usual way (preferred during more recent procedures). The location of the commissures were marked on the felt strip (Figure 2, C). The Sapien valve was then slowly deployed under direct visualization, with first-operator manipulation to ensure final position of the base of the Sapien valve 3 to $4 \mathrm{~mm}$ atrially ( $80 \%$ ventricular/ $20 \%$ atrial; Video 3). The references drawn on the felt strip were used to align the commissures of the THV with the assumed localizations of the trigones anteriorly. The anchoring sutures were secured to the soft felt cuff and Sapien frame and tied into place (Figure 2, D, and Video 4). Postdilatation with or without extra volumes added to the balloon was then performed in most cases (Video 5). Occasionally, additional pledgets or patches were placed to seal possible leaks. When the valve was judged

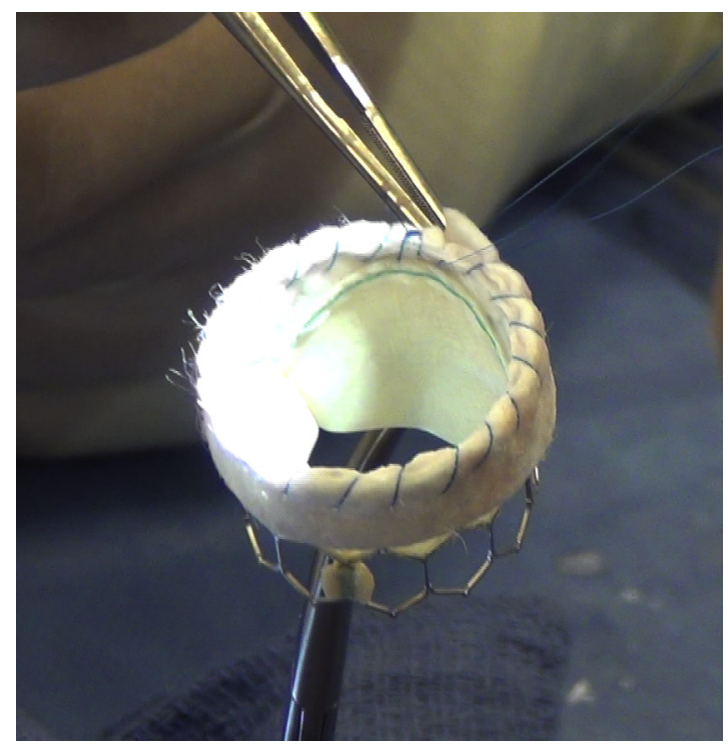

VIDEO 2. Preparation of the transcatheter valve. A felt strip is sutured onto the frame of the inflow of the Edwards Sapien 3 valve (Edwards Lifesciences, Irvine, Calif). Video available at: http://www.jtcvsonline. org/article/S0022-5223(18)30727-X/fulltext.

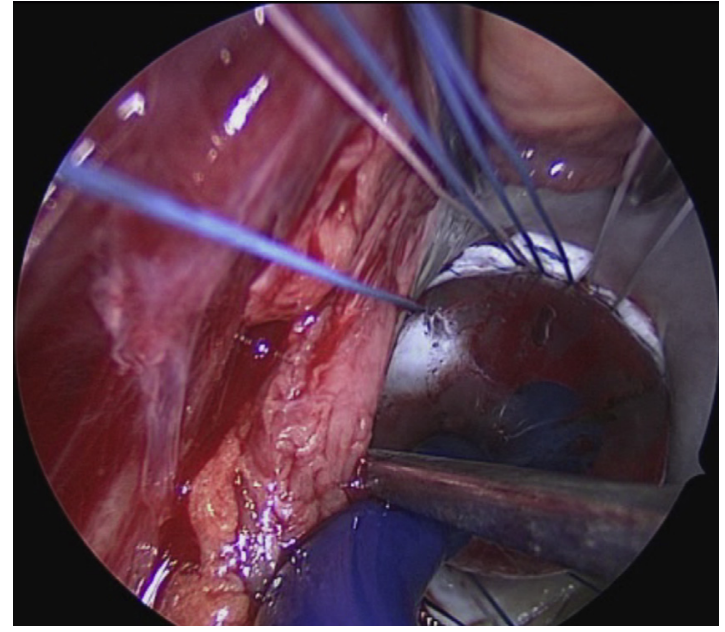

VIDEO 3. Valve deployment. The valve is slowly deployed under direct visualization with continuous positioning for an $80 \% / 20 \%$ ventricular/ atrial placement. Video available at: http://www.jtcvsonline.org/article/ S0022-5223(18)30727-X/fulltext.

impermeable (Video 6), the left atriotomy was closed. Transesophageal echocardiography was used to evaluate valve function and exclude LVOT obstruction in the operating room (Figure 2, $E$ and $F$ ). Patients were discharged on a regimen of low-dose aspirin combined with oral anticoagulation with warfarin indefinitely.

\section{End Points}

Primary end points were technical success assessed according to the criteria of the Mitral Valve Academic Research Consortium ${ }^{28}$ and 30-day mortality. Technical success was defined as the absence of procedural mortality, successful access, delivery, and retrieval of the device delivery system, successful deployment and correct positioning of the first intended implant, and freedom from surgical conversion or reintervention related to the device or vascular access. Secondary end points included the occurrence of procedural and postprocedural complications, new-onset atrial fibrillation, and change in New York Heart Association (NYHA) class at 30 days.

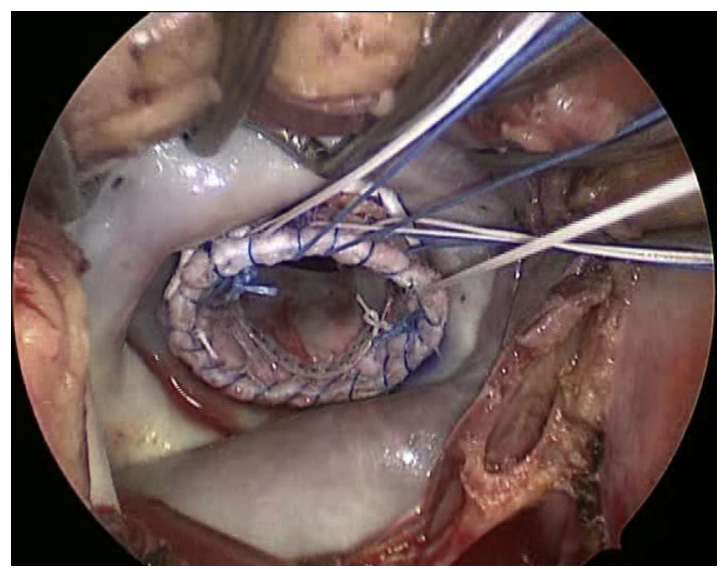

VIDEO 4. Valve sewing. The sutures are placed through the Sapien 3 (Edwards Lifesciences, Irvine, Calif) frame and felt strip and tied into place. Video available at: http://www.jtcvsonline.org/article/S0022-5223(18) 30727-X/fulltext. 


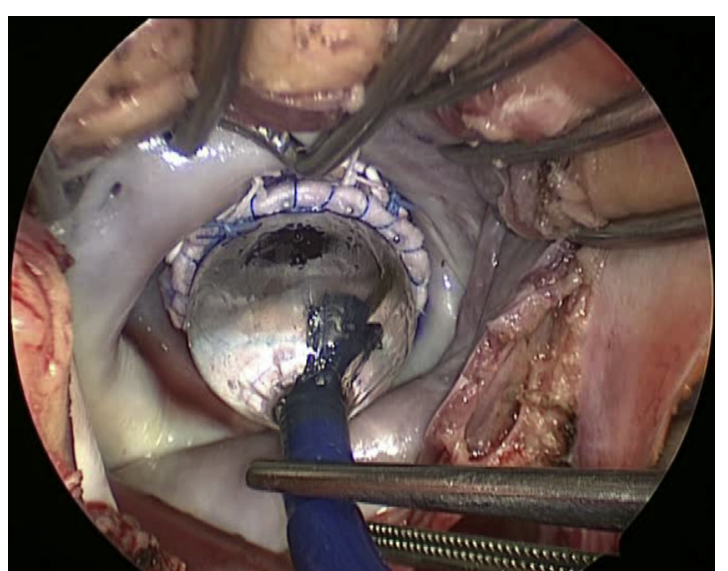

VIDEO 5. Postdilation. The valve is postdilated, generally adding 1 to $2 \mathrm{cc}$ to the nomimal volume of the delivery catheter balloon. Video available at: http://www.jtcvsonline.org/article/S0022-5223(18)30727-X/fulltext.

\section{Follow-up}

Follow-up at 30 days consisted of clinical and echocardiographic assessment generally performed at the primary institution. For follow-ups beyond 30 days, patients were contacted via phone and vital and functional status were recorded.

\section{Statistical Analysis}

Continuous variables are expressed as mean $\pm \mathrm{SD}$, and were compared using a 2 -sided $t$ test. Categorical variables are reported as counts and percentages, and were compared using the $\chi^{2}$ test. The paired $t$ test and the Wilcoxon signed rank test were used for the comparison of paired variables. Predictors of mortality were explored using Cox regression. Statistical significance was assumed with a 2-tailed $P$ value $<.05$. Data were analyzed in SPSS (version 21; IBM Corp, Armonk, NY).

\section{RESULTS}

\section{Baseline Characteristics}

Twenty-six patients ( $92 \%$ female) treated consecutively at 6 North American centers between April 20, 2015 and

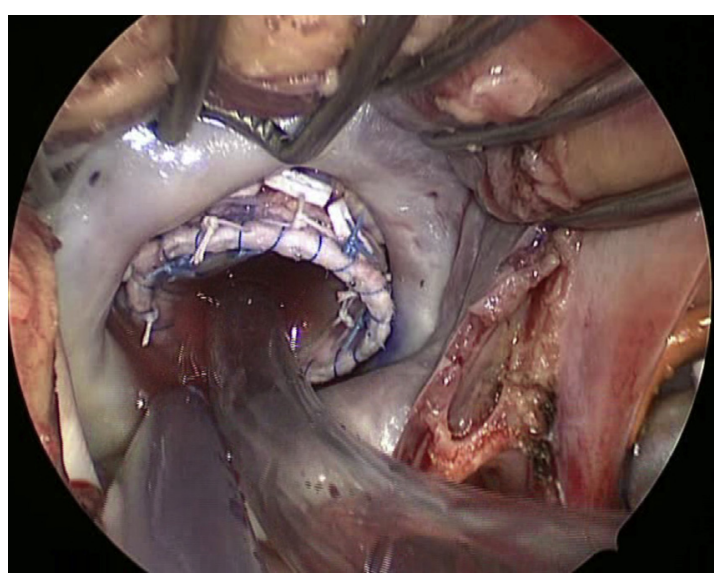

VIDEO 6. Final result. A fluid retention test is performed by filling the left ventricle with saline to confirm optimal annular sealing. Video available at: http://www.jtcvsonline.org/article/S0022-5223(18)30727-X/fulltext.
September 1, 2017 were included in this analysis. The baseline characteristics are summarized in Table 1. The mean age of the patients was $78 \pm 7$ years with a mean Society of Thoracic Surgeon predicted risk of mortality for mitral valve replacement of $9.4 \pm 4.8 \%$ and a mean EuroScore II of $8.9 \pm 4.7 \%$, both indicative of very high surgical risk. Except for 1 (NYHA II), all patients were in NYHA class III or IV at baseline, and 6 patients $(23 \%)$ underwent emergent treatment because of intractable heart failure. Secondary pulmonary hypertension $(81 \%)$ and chronic renal failure $(69 \%)$ were highly prevalent. The invasive mean cardiac index was reduced $\left(2.2 \pm 0.8 \mathrm{~L} / \mathrm{min} / \mathrm{m}^{2}\right)$, whereas the mean pulmonary capillary wedge pressure $(26 \pm 5 \mathrm{~mm} \mathrm{Hg})$ was increased. Five patients $(19 \%)$ had previous cardiac surgery (3 for

TABLE 1. Baseline clinical and hemodynamic characteristics $(\mathbf{N}=\mathbf{2 6})$

\begin{tabular}{lc}
\hline \multicolumn{1}{c}{ Characteristic } & Value \\
\hline Age, y & $78 \pm 7$ \\
Female sex & $24(92)$ \\
BMI & $28.8 \pm 4.7$ \\
EuroScore II, \% & $8.9 \pm 4.7$ \\
STS PROM, \% & $9.4 \pm 4.8$ \\
NYHA functional class & \\
II & $1(4)$ \\
III & $14(54)$ \\
IV & $11(42)$ \\
Hospitalitzations for HF during the past year & $22(85)$ \\
Comorbidities & \\
Coronary artery disease & $8(31)$ \\
$\quad$ Previous MI & $3(12)$ \\
$\quad$ Previous PCI & $5(19)$ \\
$\quad$ Previous CABG & $2(8)$ \\
Previous aortic valve replacement & $3(12)$ \\
Previous MV intervention & $2(8)$ \\
Pulmonary hypertension* & $21(81)$ \\
Chronic lung disease & $9(35)$ \\
Atrial fibrillation & $7(27)$ \\
Past cerebrovascular event & $3(12)$ \\
Chronic renal failure $(\mathrm{GFR}<60$ mL/min) & $18(69)$ \\
Diabetes mellitus & $11(42)$ \\
Arterial hypertension & $22(85)$ \\
Invasive hemodynamic measurments $\dagger$ & \\
Cardiac index, L/min/m ${ }^{2}$ & $2.2 \pm 0.8$ \\
Systolic PA pressure, mm Hg & $60 \pm 14$ \\
Diastolic PA pressure, mm Hg & $26 \pm 6$ \\
Mean PA pressure, mm Hg & $39 \pm 10$ \\
Mean PCWP, mm Hg & $26 \pm 5$ \\
PCWP V wave, mm Hg & $36 \pm 10$ \\
\hline BMI, Body & \\
\hline
\end{tabular}

BMI, Body mass index; STS PROM, Society of Thoracic Surgeons predicted risk of mortality; NYHA, New York Heart Association; $H F$, heart failure; $M I$, myocardial infarction; $P C I$, percutaneous coronary intervention; $C A B G$, coronary artery bypass graft; $M V$, mitral valve; $G F R$, glomerular filtration rate; $P A$, pulmonary artery; $P C W P$, pulmonary artery wedge pressure. *Defined as estimated or measured sPAP $>40 \mathrm{~mm} \mathrm{Hg}$. †Obtained in a subgroup of 14 patients. 
TABLE 2. Baseline cardiac imaging

\begin{tabular}{|c|c|c|c|c|}
\hline & MS $(\mathbf{n}=13)$ & $\operatorname{MR}(\mathbf{n}=\mathbf{9})$ & Mixed $(n=4)$ & $P$ value \\
\hline \multicolumn{5}{|l|}{ Echocardiography } \\
\hline LVEF, \% & $66 \pm 9$ & $65 \pm 8$ & $63 \pm 10$ & .84 \\
\hline Mitral valve area, $\mathrm{cm}^{2}$ & $1.1 \pm 0.2$ & $1.7 \pm 0.9$ & $1.4 \pm 0.6$ & .04 \\
\hline Peak transmitral gradient, $\mathrm{mm} \mathrm{Hg}$ & $22 \pm 11$ & $18 \pm 2$ & $24 \pm 8$ & .49 \\
\hline Mean transmitral gradient, $\mathrm{mm} \mathrm{Hg}$ & $13 \pm 5$ & $6 \pm 3$ & $10 \pm 4$ & .008 \\
\hline No/trivial MR & 1 & 0 & 0 & - \\
\hline MR grade $1+$ & 4 & 0 & 0 & - \\
\hline MR grade $2+$ & 7 & 0 & 0 & - \\
\hline MR grade $3+$ & 1 & 0 & 3 & - \\
\hline MR grade $4+$ & 0 & 9 & 1 & - \\
\hline Systolic pulmonary artery pressure, $\mathrm{mm} \mathrm{Hg}$ & $63 \pm 13$ & $56 \pm 13$ & $48 \pm 15$ & .29 \\
\hline Moderate or severe aortic stenosis & $4(31)$ & $7(78)$ & 0 & - \\
\hline Moderate or severe aortic regurgitation & $1(8)$ & 0 & 0 & - \\
\hline Mean LVOT gradient, $\mathrm{mm} \mathrm{Hg}$ & $4 \pm 2$ & $3 \pm 2$ & $3 \pm 1$ & .45 \\
\hline Peak LVOT gradient, $\mathrm{mm} \mathrm{Hg}$ & $7 \pm 2$ & $6 \pm 4$ & $6 \pm 1$ & .70 \\
\hline \multicolumn{5}{|l|}{ Cardiac $\mathrm{CT} \dagger$} \\
\hline $\mathrm{MV}$ area, $\mathrm{cm}^{2}$ & $1.2 \pm 0.4$ & $2.1 \pm 1.4$ & $1.5 \pm 0.3$ & .09 \\
\hline MV annulus area, $\mathrm{mm}^{2}$ & $398.7 \pm 106.8$ & $588.3 \pm 143.0$ & $426.4 \pm 61.3$ & .003 \\
\hline MV annulus perimeter, $\mathrm{mm}$ & $81.0 \pm 10.5$ & $95.0 \pm 9.8$ & $88.0 \pm 9.4$ & .008 \\
\hline Maximal MV annulus diameter, $\mathrm{mm}$ & $29.2 \pm 4.0$ & $32.6 \pm 5.8$ & $31.4 \pm 1.3$ & .13 \\
\hline Average MV annulus diameter, $\mathrm{mm}$ & $21.9 \pm 2.8$ & $27.8 \pm 3.3$ & $23.0 \pm 2.0$ & .0009 \\
\hline Area-derived MV annulus diameter, $\mathrm{mm}$ & $22.2 \pm 2.9$ & $27.7 \pm 3.2$ & $23.3 \pm 1.7$ & .002 \\
\hline Perimeter-derived $\mathrm{MV}$ annulus diameter, $\mathrm{mm}$ & $25.4 \pm 3.3$ & $30.6 \pm 3.2$ & $28.0 \pm 3.0$ & .005 \\
\hline Simulated systolic neo-LVOT area, $\mathrm{mm}^{2}$ & $125.2 \pm 62.6$ & $144.0 \pm 87.2$ & $112.3 \pm 48.6$ & .62 \\
\hline Simulated relative LVOT reduction, $\%$ & $58 \pm 15$ & $65 \pm 17$ & $65 \pm 15$ & .43 \\
\hline
\end{tabular}

$M S$, Mitral stenosis; $M R$, mitral regurgitation; $L V E F$, left ventricular ejection fraction; $L V O T$, left ventricular outflow tract; $C T$, computed tomography; $M V$, mitral valve. $* P$ values compare MS versus MR groups. †Measurements performed during diastole ( $75 \%$ phase) unless otherwise specified.

aortic valve replacement, 1 for coronary artery bypass grafting, 1 for combined coronary artery bypass grafting and mitral valve repair) and 1 patient had insufficient reduction of predominant MR after implantation of 2 MitraClips (Abbott, Santa Ana, Calif).

\section{Baseline Cardiac Imaging}

According to baseline echocardiography 13 patients $(50 \%)$ had predominant MS, $9(35 \%)$ predominant MR, and $4(15 \%)$ had mixed mitral valve disease. The anatomic and functional mitral valve characteristics of each group are presented in Table 2. In addition, 12 patients $(46 \%)$ presented with significant aortic valve disease (aortic stenosis in 11 cases and aortic regurgitation in 1).

The diastolic annulus measurements performed on preoperative cardiac CT imaging showed that patients with MR had significantly larger annular areas and perimeters compared with patients with predominant MS (both $P<.01$ ). Areas ranged from $258 \mathrm{~mm}^{2}$ to $881 \mathrm{~mm}^{2}$ whereas perimeters as small and large as 62 to $122 \mathrm{~mm}$ were observed. The mean anticipated neo-LVOT on the basis of valve simulation was found to be $<150 \mathrm{~mm}^{2}$ (range, $42-268 \mathrm{~mm}^{2}$ ) in all groups with a mean relative LVOT reduction (neo-LVOT/LVOT at the same level) of
$61 \pm 15 \%$, consistently indicating high risk of LVOT obstruction.

\section{Procedural Results}

Procedural results are summarized in Table 3. Except for 1 patient, who had right thoracotomy, median sternotomy was performed in all. Two patients $(8 \%)$ received an Edwards Sapien XT, and $24(92 \%)$ an Edwards Sapien 3 bioprosthesis. Concomitant aortic valve replacement was performed in $11(42 \%)$ of the 12 patients with significant aortic valve disease and coronary artery bypass grafting in $4(15 \%$; 1 patient had both). The remaining patient underwent staged transfemoral transcatheter aortic valve replacement (TAVR). Concomitant tricuspid valve reconstruction was performed in 1 patient $(4 \%)$ and myectomy in 2 patients $(8 \%)$, respectively. Technical success according to the Mitral Valve Academic Research Consortium criteria was achieved in all patients $(100 \%)$. The mean total procedure duration was $158 \pm 49$ minutes and mean aortic cross-clamp time was $123 \pm 34$ minutes. All patients had trace/mild MR at the end of the procedure $(100 \%)$.

Five patients died during hospital stay (19\%): 2 patients suffered acute mesenteric ischemia within 48 hours of the procedure, 1 died of prolonged respiratory failure, and the 
TABLE 3. Procedural and in-hospital outcomes $(\mathbf{N}=\mathbf{2 6})$

\begin{tabular}{|c|c|}
\hline & Value \\
\hline \multicolumn{2}{|l|}{ Procedural characteristics } \\
\hline Technical success* & $26(100)$ \\
\hline Median sternotomy & $25(96)$ \\
\hline Right thoracotomy & $1(4)$ \\
\hline \multicolumn{2}{|l|}{ Edwards Sapien XT } \\
\hline $23 \mathrm{~mm}$ & $1(4)$ \\
\hline $26 \mathrm{~mm}$ & $1(4)$ \\
\hline \multicolumn{2}{|l|}{ Edwards Sapien 3} \\
\hline $23 \mathrm{~mm}$ & $3(11)$ \\
\hline $26 \mathrm{~mm}$ & $14(54)$ \\
\hline $29 \mathrm{~mm}$ & $7(27)$ \\
\hline Procedural duration, minutes & $158 \pm 49$ \\
\hline Cross clamp time, minutes & $123 \pm 34$ \\
\hline Procedural mortality & 0 \\
\hline \multicolumn{2}{|l|}{ In-hospital outcomes } \\
\hline In-hospital mortality & $5(19)$ \\
\hline LVOT obstruction & $1(4)$ \\
\hline Major bleeding requiring surgical re-exploration & $2(8)$ \\
\hline Valve embolization & 0 \\
\hline \multicolumn{2}{|l|}{ Cerebrovascular event } \\
\hline TIA & 0 \\
\hline Ischemic stroke & $1(4)$ \\
\hline Acute renal failure requiring temporary dialysis & $4(15)$ \\
\hline Permanent pacemaker implantation & $2(8)$ \\
\hline New-onset atrial fibrillation & $7(27)$ \\
\hline Length of stay, $d$ & $13 \pm 6$ \\
\hline \multicolumn{2}{|l|}{ Echocardiographic outcomes } \\
\hline Peak transmitral gradient, $\mathrm{mm} \mathrm{Hg}$ & $9 \pm 3$ \\
\hline Mean transmitral gradient, $\mathrm{mm} \mathrm{Hg}$ & $4 \pm 2$ \\
\hline Peak LVOT gradient, $\mathrm{mm} \mathrm{Hg}$ & $8 \pm 4$ \\
\hline Mean LVOT gradient, $\mathrm{mm} \mathrm{Hg}$ & $5 \pm 3$ \\
\hline \multicolumn{2}{|l|}{ MR severity } \\
\hline No/trivial MR & 16 \\
\hline MR grade $1+$ & 9 \\
\hline MR grade $2+$ & 1 \\
\hline MR grade $3+$ & 0 \\
\hline MR grade $4+$ & 0 \\
\hline
\end{tabular}

Edwards Sapien valves are from Edwards Lifesciences (Irvine, Calif). LVOT, Left ventricular outflow tract obstruction; TIA, transient ischemic attack; $M R$, mitral regurgitation. *According to MVARC criteria.

remaining 2 had multiorgan failure. In 1 patient (4\%), a fixed anterior Sapien valve leaflet along with elevated mean transvalvular aortic gradient $(30 \mathrm{~mm} \mathrm{Hg})$ were observed.

Major bleeding requiring re-exploration occurred in 2 patients $(8 \%)$ : 1 ventricular free wall injury from a wire perforation was found and 1 small arterial bleeder originating from the pericardial surface. Both were fixed without bypass with sutures. Nondisabling stroke and acute kidney injury requiring temporary dialysis occurred in 1 $(4 \%)$ and $4(15 \%)$ patients, respectively. A permanent pacemaker was implanted in 2 patients $(8 \%)$ and 7 patients $(27 \%)$ developed new-onset atrial fibrillation after surgery.
Patients were discharged within $13 \pm 6$ days. At discharge, the peak transmitral gradient decreased from $22 \pm 9 \mathrm{~mm} \mathrm{Hg}$ to $9 \pm 3 \mathrm{~mm} \mathrm{Hg}(P<.001)$ and the mean transmitral gradient decreased from $10 \pm 5 \mathrm{~mm} \mathrm{Hg}$ to $4 \pm 2 \mathrm{~mm} \mathrm{Hg}(P<.001$; Figure 3, A). Postprocedural mean LVOT gradient was able to be measured using TTE in 21 patients and was $5 \pm 3 \mathrm{~mm} \mathrm{Hg}$. Among the 21 patients discharged alive, 11 had no or trace residual MR and 10 mild MR (Figure 3, B).

\section{Thirty-Day Outcomes and Longer-Term Follow-up}

Two patients died between discharge and 30 days (due to renal failure in the first patient and disabling stroke in the second). Thus, the 30 -day mortality was $27 \%$. Thirty-day follow-up was obtained in all of the 19 patients alive, except 1 patient who withdrew consent. NYHA class was significantly improved compared with baseline (Figure 4).

One patient with mild paravalvular leak (PVL) at discharge experienced hemolysis related to progression to moderate PVL 3 months after surgery. The patient was successfully treated with postdilation of the 29-mm Sapien 3 valve using a 28-mm Z-Med balloon (B. Braun Interventional Systems, Bethlehem, Pa) and implantation of one 8-mm Amplatzer Vascular Plug (Abbott, Abbott Park, Ill). MR was reduced to grade $1+$ after plug implantation and hemolysis subsequently resolved. One patient treated via right thoracotomy underwent successful TAVR for treatment of severe aortic stenosis 6 months after the initial procedure.

Longer-term follow-up was available in 15 patients (mean follow-up duration $8.0 \pm 7.2$ months). Two patients died after 30 days ( 1 each from septic shock and respiratory failure). Among the remaining 13 patients, sustained functional improvement was observed: 6 patients were in NYHA class III, 4 in NYHA class II, and 3 in NYHA class $\mathrm{I}(P=.004)$.

Table 4 shows a comparison of the principal characteristics of the patients who died with those of the survivors. The patients who died during the follow-up period had a significantly higher logistic Euroscore II $(11.7 \pm 6.1 \%$ vs $7.4 \pm 2.9 \% ; P=.02)$, an increased pulmonary capillary wedge pressure $(29 \pm 3 \mathrm{~mm} \mathrm{Hg}$ vs $23 \pm 5 \mathrm{~mm} \mathrm{Hg} ; P=.04)$, and a higher prevalence of peripheral artery disease at baseline $(22 \%$ vs $0 \%$; $P=.04)$. In addition, a trend toward statistical significance was observed for the following factors: lower glomerular filtration rate in the deceased group $(40 \pm 16 \mathrm{~mL} / \mathrm{min}$ vs $58 \pm 27 \mathrm{~mL} / \mathrm{min} ; P=.07)$, a higher incidence of severe tricuspid regurgitation $(44 \%$ vs $12 \% ; P=.06)$, and a higher left ventricular end-diastolic pressure $(24 \pm 6 \mathrm{~mm} \mathrm{Hg}$ vs $16 \pm 6 \mathrm{~mm} \mathrm{Hg} ; P=.07)$. Cardiopulmonary bypass and cross-clamp times were prolonged in nonsurvivors, because of concomitant surgery, although these findings also did not 


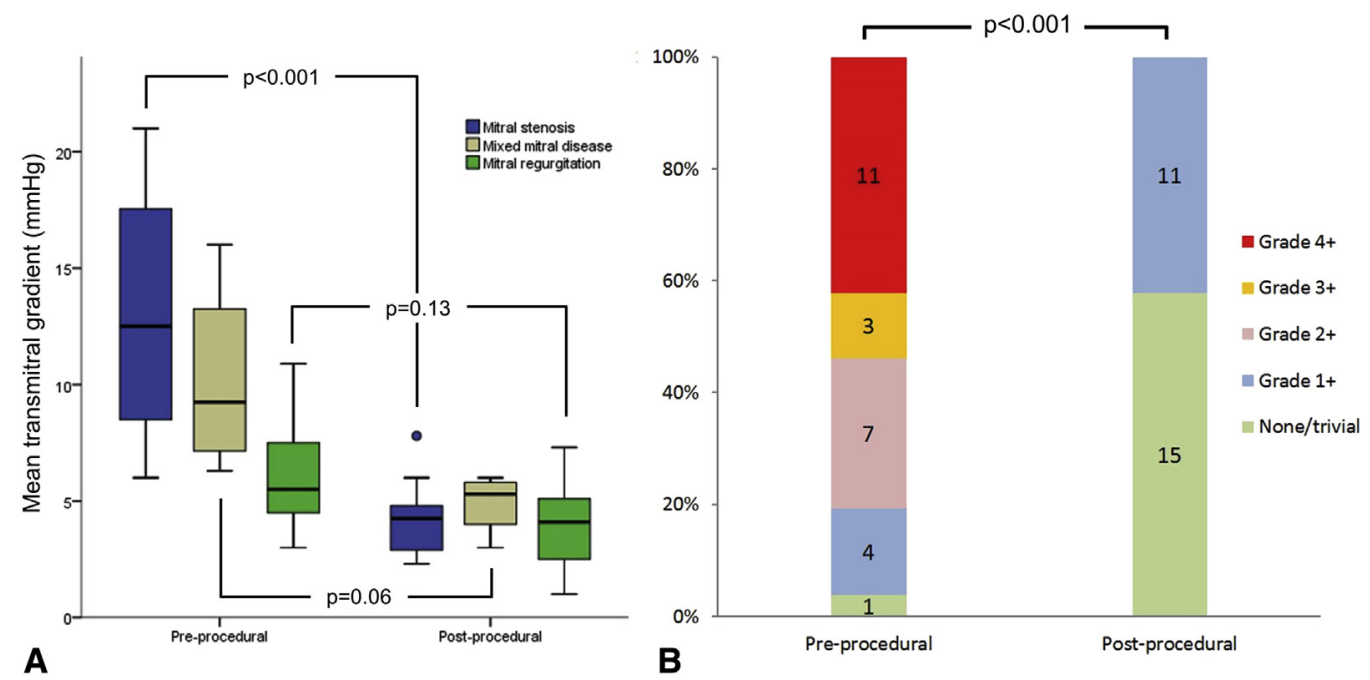

FIGURE 3. Hemodynamic changes. A, Change of the mean transmitral gradient before and immediately after the procedure according to mitral valve pathology. $P$ values are calculated using paired $t$ test. B, Change of mitral regurgitation severity before and after the procedure. The $P$ value is calculated using the Wilcoxon signed rank test.

reach statistical significance. Cox regression identified acute postprocedural kidney injury as a predictor of death (hazard ratio, 4.65; 95\% confidence interval, 1.1-19.9; $P=.038)$.

\section{DISCUSSION}

The primary findings of this study can be summarized as follows: (1) surgical transatrial implantation of a Sapien THV for treatment of severe MAC can be performed with high technical success $(100 \%)$ and with very low PVL; (2) in-hospital mortality in this cohort of sick patients was

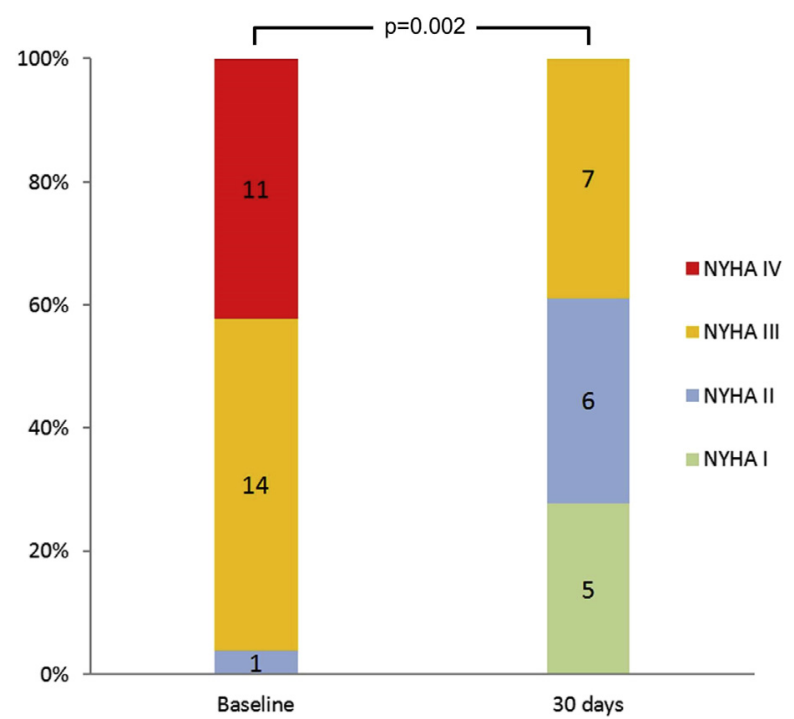

FIGURE 4. Change in New York Heart Association (NYHA) class. Change of the functional status between baseline and 30 days. The $P$ value is calculated for 18 paired values using the Wilcoxon signed rank test. high $(19 \%)$; (3) systematic resection of the anterior mitral valve leaflet allows for safe treatment of patients at high risk for LVOT obstruction; (4) despite advanced disease at baseline, relevant functional improvement was observed at 30 days.

Although minimally invasive techniques might be preferred in the settings of advanced age and surgical high risk, the direct transatrial valve implantation addresses the needs of patients who are considered ineligible for another approach because of 1 or several of the following conditions: high risk of LVOT obstruction, concomitant multivalvular and/or coronary artery disease, noncircumferential annular calcification increasing the risk of valve embolization, and extensive calcifications of the subvalvular apparatus. The occurrence of any 1 of these exclusion criteria for the transseptal approach might be as high as $75 \%$ of all patients with MAC and mitral valve disease.

Recently, the outcomes of various transcatheter techniques have been investigated in a global registry including 64 MAC patients from 32 centers of whom $41 \%$ were treated in a fully percutaneous fashion using transfemoral transseptal access. ${ }^{29}$ Compared with patients treated via either the transapical $(46 \%)$ or the transatrial $(14 \%)$ approach, the patients in the transseptal group had a lower technical success of $65 \%$ versus $71 \%$ and $89 \%$, respectively. In this registry, the 30 day all-cause mortality was $29.7 \%$.

The high mortality rate observed in this early experience with transatrial THV implantation has to be interpreted in the light of patient comorbidities as well as technical considerations. Indeed, the patients included were highly symptomatic and almost one-third was treated emergently during hospital admission for decompensated heart failure. Pulmonary hypertension, low cardiac output, and chronic 
TABLE 4. Comparison between the patients alive and those who died during follow-up

\begin{tabular}{|c|c|c|c|}
\hline & Alive $(n=17)$ & Deceased $(n=9)$ & $P$ value \\
\hline Age, y & $78 \pm 7$ & $78 \pm 7$ & .91 \\
\hline BMI & $29.5 \pm 4.3$ & $27.4 \pm 5.3$ & .30 \\
\hline EuroScore II, \% & $7.4 \pm 2.9$ & $11.7 \pm 6.1$ & .02 \\
\hline STS PROM, \% & $8.4 \pm 4.1$ & $11.2 \pm 5.7$ & .15 \\
\hline NYHA class IV, n (\%) & $6(35)$ & $5(56)$ & .32 \\
\hline \multicolumn{4}{|l|}{ Comorbidities, $\mathrm{n}(\%)$} \\
\hline Coronary artery disease & $4(24)$ & $4(44)$ & .27 \\
\hline Previous open-heart surgery & $3(18)$ & $2(22)$ & .78 \\
\hline Pulmonary hypertension* & $14(82)$ & $7(78)$ & .78 \\
\hline Chronic lung disease & $6(35)$ & $3(33)$ & .92 \\
\hline Peripheral artery disease & $\mathbf{0}$ & $2(22)$ & .04 \\
\hline Atrial fibrillation & $4(24)$ & $3(33)$ & .59 \\
\hline Past cerebrovascular event & $1(6)$ & $2(22)$ & .22 \\
\hline $\mathrm{GFR}, \mathrm{mL} / \mathrm{min}$ & $58 \pm 27$ & $40 \pm 16$ & .07 \\
\hline Diabetes mellitus & $7(41)$ & $4(44)$ & .87 \\
\hline \multicolumn{4}{|l|}{ Valvular heart disease, $\mathrm{n}(\%)$} \\
\hline Predominant MR & $4(24)$ & $5(56)$ & .10 \\
\hline Predominant MS & $10(59)$ & $3(33)$ & .22 \\
\hline Mixed mitral valve disease & $3(18)$ & $1(7)$ & .66 \\
\hline Severe TR & $2(12)$ & $4(44)$ & .06 \\
\hline \multicolumn{4}{|l|}{ Invasive hemodynamic measurments } \\
\hline Mean PCWP, mm Hg & $23 \pm 5$ & $29 \pm 3$ & .04 \\
\hline Mean LVEDP, mm Hg & $16 \pm 6$ & $24 \pm 6$ & .07 \\
\hline \multicolumn{4}{|l|}{ Procedural characteristics } \\
\hline Procedure duration, minutes & $148 \pm 40$ & $173 \pm 61$ & .30 \\
\hline Cross-clamp time, minutes & $113 \pm 28$ & $140 \pm 40$ & .11 \\
\hline Concomitant AVR, n (\%) & $5(29)$ & $6(67)$ & .07 \\
\hline Concomitant CABG, n (\%) & $2(12)$ & $2(22)$ & .48 \\
\hline Urgent procedure, $\mathrm{n}(\%)$ & $3(18)$ & $3(33)$ & .37 \\
\hline Acute kidney injury, n (\%) & $1(6)$ & $3(33)$ & .07 \\
\hline Simulated systolic neo-LVOT area, $\mathrm{mm}^{2}$ & $140 \pm 65$ & $105 \pm 70$ & .30 \\
\hline Simulated relative LVOT reduction, $\%$ & $60 \pm 14$ & $57 \pm 19$ & .76 \\
\hline
\end{tabular}

Statisctically significant values or those showing a trend towards statistical significance are shown in bold. BMI, Body mass index; STS PROM, Society of Thoracic Surgeons predicted risk of mortality; NYHA, New York Heart Association; GFR, glomerular filtration rate; $M R$, mitral regurgitation; $M S$, mitral stenosis; TR, tricuspid regurgitation; $P C W P$, pulmonary capillary wedge pressure; $L V E D P$, left ventricular enddiastolic pressure; $A V R$, aortic valve replacement; $C A B G$, coronary artery bypass graft; $L V O T$, left ventricular outflow tract. *Defined as estimated or measured sPAP $>40 \mathrm{~mm} \mathrm{Hg}$.

renal failure, 3 established predictors of mortality after cardiac surgery, were highly prevalent, resulting in overall high surgical risk. Furthermore, 5 patients $(19 \%)$ underwent reoperative cardiac surgery. It is of note that the Society of Thoracic Surgeons score certainly underestimates the risk of mortality in this particular context, because it does not account for multiple valve surgery that was performed in almost half of the patients. Although of explorative nature, the comparison of the principal baseline and procedural characteristics of the patients alive with those of the patients who died during the follow-up period provides important information about the potential effect on mortality of poor hemodynamic condition before surgery, complex valvular heart disease (in particular concomitant severe tricuspid regurgitation), as well as the presence of chronic kidney disease and the postprocedural occurrence of acute kidney injury. Improved patient selection along with in-hospital optimization before surgery might mitigate these comorbid risks.

Technical aspects that were part of the learning curve, might also have affected mortality. Extensive surgical valve decalcification, which was occasionally performed during our early experience in patients with severely restricted valve opening, was found to carry a high risk of systemic debris embolization with potential lethal consequences (in particular acute mesenteric ischemia) and was limited to the strict necessary or, whenever possible, even abandoned in the patients treated more recently. More generally, severe MAC itself has been associated with increased cardiovascular and all-cause mortality ${ }^{9}$ that might be accentuated in the setting of cardiovascular interventions. In a recent study, patients with severe MAC were reported 
to have significantly higher 30 -day $(6.9 \%)$ and 1 -year $(21.7 \%)$ mortality after TAVR, ${ }^{6}$ which might represent hemodynamic, conduction, as well as neurologic sequelae.

Compared with the initially described procedure, ${ }^{21} 3$ additional steps have been implemented with the goal to optimize sizing and minimize the risk of PVL that is increased because of the irregular anatomy of the annular calcium rim. First, balloon sizing was used in almost all patients because it provides reliable measurements of the annular size accounting for the individual annular stiffness. Second, a soft felt strip was sutured to the inflow part of stent valve frame to optimize valve apposition. Third, several pledgeted sutures were placed on the leaflets tissue covering the annular calcium and therefore provide no anchoring because the leaflet tissue is often attenuated and thin, but rather to aim to seal possible leaks. Moreover, evolution from the Sapien XT to the Sapien 3 valve has permitted to further decrease the risk of PVL thanks to the presence of the outer skirt at the inflow of the THV. These measures resulted in the remarkably low rate of residual MR, valve embolization, and need of reintervention for mitral valve dysfunction reported in this study. This is noteworthy because paravalvular residual MR not infrequently leads to hemolysis, as observed in 1 patient of our cohort, in whom percutaneous PVL closure was successful. Of note, no major atrioventricular groove injury was observed, although this risk does exist because of the mechanism of deployment.

Another important technical aspect relates to the risk of LVOT obstruction that has been described to occur in almost $10 \%$ of the MAC patients who underwent transcatheter valve replacement. ${ }^{29}$ This complication, generally related to the displacement of the anterior mitral valve leaflet toward the LVOT, can be usually avoided through preemptive electric cautery laceration of the anterior leaflet during transseptal approach, ${ }^{30}$ splitting of the anterior leaflet from transapical, ${ }^{31}$ or preprocedure alcohol septal ablation to reduce septal thickness, ${ }^{32}$ or resection of the anterior leaflet, as enabled through the transatrial approach. A recent study reported that patients with a predicted neo-LVOT area $\leq 189.4 \mathrm{~mm}^{2}$ are at risk for an increase of the peak LVOT gradient of $\geq 10 \mathrm{~mm} \mathrm{Hg}$ after transpical or transseptal valve implantation. ${ }^{33}$ Despite a mean simulated neo-LVOT area below this limit in all but 3 patients and close location of the prosthesis to the interventricular septum in all, LVOT obstruction occurred in only 1 patient in our cohort, the one with the smallest annular area, most likely because of excessive oversizing in conjunction with too ventricular placement of the valve. Indeed, excessive oversizing might result in either displacement of the anterior part of the annulus into the LVOT or increased exposure of the part of the valve stent frame covered by the skirt. In addition, acute leaflet dysfunction without evidence of leaflet thrombosis (anterior leaflet stuck in closed position), probably because of nonuniform leaflet opening and closing consecutive to stent frame underexpansion, was observed in the same patient. According to our experience, patients with a mitral annulus area $<300 \mathrm{~mm}^{2}$ might be at higher risk of complications and should undergo careful evaluation.

Although MAC patients might be at increased risk of conduction disturbances because of calcific infiltration of the aortomitral curtain or the interventricular septum, ${ }^{6}$ the incidence of new permanent pacemaker implantation remained relatively low (2 patients; $8 \%$ ) and was linked to concomitant aortic valve replacement in 1 patient. The incidence of new-onset atrial fibrillation $(27 \%)$ was comparable with those observed in patients who underwent surgical mitral valve replacement. ${ }^{34}$

In summary, transatrial THV implantation might address the significant need of patients not eligible for other transcatheter techniques because of anatomic considerations. Compared with the conventional surgical approach, transatrial implantation might present the following advantages: low risk of debris embolization, circumflex artery injury, and atrioventricular conduction disturbance, as well as shorter procedural duration. In addition, the stented valve might offer a larger valve area compared with surgical valves of similar size. However, 30-day mortality was high in our cohort. Improved patient selection and the development of hybrid strategies combining surgical and transcatheter techniques $^{14,35}$ (eg, TAVR) in the setting of multiple valvular disease might be needed to improve the outcomes of this novel surgical technique.

\section{Limitation}

This study investigated the outcomes of a small number of patients with a particular risk and anatomic constellation and might not be transferable to other categories of patients and other surgical or transcatheter approaches. Because of the nonrandomized design and the absence of a control group, comparisons could only be performed indirectly on the basis of the literature. Because systematic Holter monitoring was not conducted, the rate of new-onset atrial fibrillation might have been underestimated in our cohort.

\section{CONCLUSIONS}

Transatrial implantation of a THV for the treatment of MAC is associated with high technical success despite unfavorable anatomy. In this early experience of very high surgical risk patients, 30-day all-cause mortality was high. Patients at particular risk appear to be those with chronic kidney disease requiring multiple valve surgery.

\section{Conflict of Interest Statement}

Dr Praz is a consultant for Edwards Lifesciences; Dr Khalique has received speaker fees from Edwards 
Lifescience; Dr Lee is a speaker and consultant for Abiomed; Dr Islam is a consultant for Edwards Lifesciences and Medtronic; Dr Guerrero has received research grant support from Edwards Lifescience; Dr Kaneko is a consultant for Edwards Lifesciences, Abbott, and Medtronic; Dr Kodali has received research support from Edwards Lifesciences, and Medtronic, consulting fees from Claret Medical and Abbott, and holds equity in Dura Biotech and Thubrikar Aortic Valve, Inc; Dr Bapat is a consultant to Edwards Lifesciences, and Medtronic. Dr Borger has received speaker's honoraria and consulting fees from Edwards Lifescience, Medtronic, CryoLife, and St. Jude; . Dr George has received consulting fees for Edwards Lifesciences, Medtronic, and Boston Scientific. All other authors have nothing to disclose with regard to commercial support.

\section{References}

1. Kanjanauthai S, Nasir K, Katz R, Rivera JJ, Takasu J, Blumenthal RS, et al Relationships of mitral annular calcification to cardiovascular risk factors: the multi-ethnic study of atherosclerosis (MESA). Atherosclerosis. 2010;213: 558-62.

2. Allison MA, Cheung P, Criqui MH, Langer RD, Wright CM. Mitral and aortic annular calcification are highly associated with systemic calcified atherosclerosis. Circulation. 2006;113:861-6.

3. Fertman MH, Wolff L. Calcification of the mitral valve. Am Heart J. 1946:31: 580-9.

4. Foley PW, Hamaad A, El-Gendi H, Leyva F. Incidental cardiac findings on computed tomography imaging of the thorax. BMC Res Notes. 2010;3:326.

5. Eleid MF, Foley TA, Said SM, Pislaru SV, Rihal CS. Severe mitral annular calcification: multimodality imaging for therapeutic strategies and interventions. JACC Cardiovasc Imaging. 2016;9:1318-37.

6. Abramowitz Y, Kazuno Y, Chakravarty T, Kawamori H, Maeno Y, Anderson D, et al. Concomitant mitral annular calcification and severe aortic stenosis: prevalence, characteristics and outcome following transcatheter aortic valve replacement. Eur Heart J. 2017;38:1194-203.

7. Asselbergs FW, Mozaffarian D, Katz R, Kestenbaum B, Fried LF, Gottdiener JS, et al. Association of renal function with cardiac calcifications in older adults: the cardiovascular health study. Nephrol Dial Transplant. 2009;24:834-40.

8. Davutoglu V, Yilmaz M, Soydinc S, Celen Z, Turkmen S, Sezen Y, et al. Mitral annular calcification is associated with osteoporosis in women. Am Heart J. 2004;147:1113-6.

9. Fox CS, Vasan RS, Parise H, Levy D, O’Donnell CJ, D'Agostino RB, et al. Mitral annular calcification predicts cardiovascular morbidity and mortality: the Framingham heart study. Circulation. 2003;107:1492-6.

10. Carrel TP, Weber A. Selective, segmental decalcification: a safe alternative to extensive debridement of a severely calcified annulus during repair of mitral regurgitation. Interact Cardiovasc Thorac Surg. 2016;23:665-7.

11. Said SM, Schaff HV. An alternate approach to valve replacement in patients with mitral stenosis and severely calcified annulus. J Thorac Cardiovasc Surg. 2014; 147:e76-8.

12. Carpentier AF, Pellerin M, Fuzellier JF, Relland JY. Extensive calcification of the mitral valve anulus: pathology and surgical management. J Thorac Cardiovasc Surg. 1996;111:718-29; discussion: 729-30.

13. Feindel CM, Tufail Z, David TE, Ivanov J, Armstrong S. Mitral valve surgery in patients with extensive calcification of the mitral annulus. J Thorac Cardiovasc Surg. 2003;126:777-82

14. Greason KL, Sandhu GS, Nkomo VT, King KS, Joyce DL, Williamson EE, et al. Transcatheter aortic valve insertion after previous mitral valve operation. J Thorac Cardiovasc Surg. 2017;154:810-5.

15. Mihaljevic T, Koprivanac M, Kelava M, Smedira NG, Lytle BW, Blackstone EH. Mitral valve replacement in patients with severely calcified mitral valve annulus: surgical technique. J Thorac Cardiovasc Surg. 2013;146:233-5.

16. Lee R, Fukuhara S, George I, Borger MA. Mitral valve replacement with a transcatheter valve in the setting of severe mitral annular calcification. J Thorac Cardiovasc Surg. 2016;151:e47-9.
17. Murashita T, Suri RM, Daly RC. Sapien XT transcatheter mitral valve replacement under direct vision in the setting of significant mitral annular calcification. Ann Thorac Surg. 2016;101:1171-4.

18. Baumgarten H, Squiers JJ, Brinkman WT, DiMaio JM, Gopal A, Mack MJ, et al. Implantation of transcatheter aortic prosthesis in 3 patients with mitral annular calcification. Ann Thorac Surg. 2016;102:e433-5.

19. Praz F, Windecker S, Huber C, Carrel T, Wenaweser P. Expanding indications of transcatheter heart valve interventions. JACC Cardiovasc Interv. 2015;8:1777-96.

20. Ghosh-Dastidar M, Bapat V. Transcatheter valve implantation in mitral annula calcification during open surgery: extended collar technique. Ann Thorac Surg. 2017:104:e303-5.

21. Carrel T, Wenaweser P, Reineke S, Simon R, Eberle B, Windecker S, et al Worldwide first surgical implantation of a transcatheter valved stent in mitra position. Cardiovasc Med. 2012;15:202-5

22. Langhammer B, Huber C, Windecker S, Carrel T. Surgical antegrade transcatheter mitral valve implantation for symptomatic mitral valve disease and heavily calcified annulus. Eur J Cardiothorac Surg. 2017;51:382-4.

23. El Sabbagh A, Eleid MF, Foley TA, Al-Hijji MA, Daly RC, Rihal CS, et al. Direct transatrial implantation of balloon-expandable valve for mitral stenosis with severe annular calcifications: early experience and lessons learned. Eur J Cardiothorac Surg. 2018;53:162-9.

24. Nishimura RA, Otto CM, Bonow RO, Carabello BA, Erwin JP III, Guyton RA, et al. 2014 AHA/ACC guideline for the management of patients with valvular heart disease: a report of the American College of Cardiology/American Heart Association task force on practice guidelines. J Thorac Cardiovasc Surg. 2014;148:e1-132.

25. Vahanian A, Alfieri O, Andreotti F, Antunes MJ, Baron-Esquivias G, Baumgartner H, et al. Guidelines on the management of valvular heart disease (version 2012): the joint task force on the management of valvular heart disease of the European Society of Cardiology (ESC) and the European Association for Cardio-Thoracic Surgery (EACTS). Eur J Cardiothorac Surg. 2012;42:S1-44.

26. Baumgartner H, Hung J, Bermejo J, Chambers JB, Evangelista A, Griffin BP, et al. Echocardiographic assessment of valve stenosis: EAE/ASE recommendations for clinical practice. J Am Soc Echocardiogr. 2009;22:1-23. quiz: 101-2.

27. Blanke P, Naoum C, Dvir D, Bapat V, Ong K, Muller D, et al. Predicting LVOT obstruction in transcatheter mitral valve implantation: concept of the neo-LVOT. JACC Cardiovasc Imaging. 2017;10:482-5.

28. Stone GW, Adams DH, Abraham WT, Kappetein AP, Genereux P, Vranckx P, et al. Clinical trial design principles and endpoint definitions for transcatheter mitral valve repair and replacement: part 2: endpoint definitions: a consensus document from the mitral valve academic research consortium. J Am Coll Cardiol. 2015;66:308-21.

29. Guerrero M, Dvir D, Himbert D, Urena M, Eleid M, Wang DD, et al Transcatheter mitral valve replacement in native mitral valve disease with severe mitral annular calcification: results from the first multicenter global registry. JACC Cardiovasc Interv. 2016;9:1361-71.

30. Babaliaros VC, Greenbaum AB, Khan JM, Rogers T, Wang DD, Eng MH, et al Intentional percutaneous laceration of the anterior mitral leaflet to prevent outflow obstruction during transcatheter mitral valve replacement: first-in-human experience. JACC Cardiovasc Interv. 2017:10:798-809.

31. Lee R, Hui DS, Helmy TA, Lim MJ. Transapical mitral replacement with anterior leaflet splitting: a novel technique to avoid left ventricular outflow tract obstruction. J Thorac Cardiovasc Surg. 2018;155:e95-8.

32. Guerrero M, Wang DD, Himbert D, Urena M, Pursnani A, Kaddissi G, et al. Short-term results of alcohol septal ablation as a bail-out strategy to treat severe left ventricular outflow tract obstruction after transcatheter mitral valve replacement in patients with severe mitral annular calcification. Catheter Cardiovasc Interv. 2017;90:1220-6.

33. Wang DD, Eng MH, Greenbaum AB, Myers E, Forbes M, Karabon P, et al. Validating a prediction modeling tool for left ventricular outflow tract (LVOT) obstruction after transcatheter mitral valve replacement (TMVR). Catheter Cardiovasc Interv. December 11, 2017 [Epub ahead of print].

34. Maisel WH, Rawn JD, Stevenson WG. Atrial fibrillation after cardiac surgery. Ann Intern Med. 2001;135:1061-73.

35. Squiers JJ, Potluri S, Brinkman WT, DiMaio JM. Systematic review of transcatheter aortic valve replacement after previous mitral valve surgery J Thorac Cardiovasc Surg. 2018:155:63-5.e5.

Key Words: mitral annular calcification, transcatheter valve, mitral valve surgery, mitral regurgitation, mitral stenosis 